\title{
SENSORLESS SPEED ESTIMATION OF BRUSHLESS DOUBLY-FED RELUCTANCE GENERATOR USING ACTIVE POWER BASED MRAS BY PI AND ANFIS CONTROLLER
}

\author{
M. ANKARAO ${ }^{1}$, G. PRAVALLIKA ${ }^{2} \&$ S. SRIDHAR ${ }^{3}$ \\ ${ }^{1}$ Assistant Professor, JNTUA College of Engineering (Autonomous), Ananthapuramu, Andhra Pradesh, India \\ ${ }^{2}$ Student, JNTUA College of Engineering (Autonomous), Ananthapuramu, Andhra Pradesh India \\ ${ }^{3}$ Assistant Professor, JNTUA College of Engineering (Autonomous), Ananthapuramu, Andhra Pradesh, India
}

This paper proposes the principles of sensorless speed estimation of BDFRG based on the model reference adaptive system (MRAS), using the efficient real powers from the $d$ and $q$ circuits. The functional part of the MRAS is given by the difference of the active powers of the secondary d-q circuits. In this paper the speed error, angular position, primary and secondary $d$ and $q$ currents, torque, real power and reactive power to be measured at different operating conditions. The analysis is confirmed through comparison of various simulations using both PI controller and ANFIS controller.
\end{abstract}

KEYWORDS: Model Reference Adaptive System, Brushless doubly fed Reluctance Generator, primary field oriented control, PI and ANFIS Controllers

Received: May 13, 2020; Accepted: Jun 03, 2020; Published: Aug 05, 2020; Paper Id.: IJMPERDJUN2020628

\section{INTRODUCTION}

The BDFRG is a part of doubly fed machines family. BDFRG is generally used for wind power applications [1].The operation of the BDFIM and BDFRG is same but only the difference is, In BDFRG there is no need of rotor winding due to this the rotor copper losses will be reduced, Thereby increasing the efficiency of the BDFRG drive. Moreover, BDFRG have the advantages like high reliability [2], higher efficiency, easy in controllability and reducing their maintenance. Moreover, at no load BDFRG shows a stable operation than BDFIM in entire speed range [3]. The design of BDFRG having two sinusoidal distributed stator windings with special operating frequencies and poles. It includes reluctance type of rotor having poles must be equal to the half of total number of stator poles [4]. The primary stator winding directly connected to Grid and the secondary stator winding connected to grid through a back to back voltage source converter which facilitates the bidirectional flow of power. This structure produces a magnetic coupling between windings through a position-dependent cage less reluctance rotor for the production of electromagnetic torque in the rotor. Different control techniques are used to measure the speed of BDFRG, those are vector control [5], field oriented control [6], and direct torque control [7]. All these methods include encoders for closed loop control, due to this the drive system becomes more expensive. Now a days sensor less techniques are preferred for measuring the speed of BDFRG, those are Signal injection method [8], Kalman filter [9], MRAS method [10] and Adaptive schemes. By seeing above all the methods MRAS is best method for speed estimation because it's simple in formulation and implementation. Based on the functional quantities MRAS based speed estimation can classified as Secondary winding flux(SF) based MRAS, Secondary winding Reactive power (SQ) based MRAS and Secondary winding Fictitious quantity(SX) based MRAS. In SF-MRAS the difficulty of flux estimation occurs for 
variable speed operations [11]. The instability problem at certain operating points in Q-MRAS [12]. High speed transient error occurs in X-MRAS based speed estimator [13].In this paper Secondary winding Active power (P) based MRAS is implemented to prevail over the above mentioned disadvantages.

\section{BDFRG MODELING, PRIMARY FIELD ORIENTED CONTROL (FOC) AND P-MRAS}

\section{A. BDFRG Modeling}

The pole number of the rotor is equal to

$$
\begin{aligned}
& p_{r}=\left(p_{p}+p_{s}\right) / 2 \\
& p_{r}= \pm\left(p_{p}-p_{s}\right) / 2
\end{aligned}
$$

The voltage and flux equations of primary and secondary windings of BDFRG in any rotating reference frames is articulated as

$$
\begin{aligned}
& \bar{v}_{p}=\bar{i}_{p} R_{p}+\bar{\lambda}_{p}+\omega_{p} \bar{\lambda}_{p} \\
& \bar{v}_{s}=\bar{i}_{s} R_{s}+\dot{\bar{\lambda}}_{s}+\left(\omega_{r}-\omega_{p} \bar{\lambda}_{s}\right. \\
& \bar{\lambda}_{p}=L_{p} i_{p d}+L_{p s} i_{s d}+j\left(L_{p} i_{p q}-L_{p s} i_{s q}\right)=\lambda_{p d}+j \lambda_{p q} \\
& \bar{\lambda}_{s}=L_{s} i_{s d}+L_{p s} i_{p q}+j\left(L_{s} i_{s q}-L_{p s} i_{p q}\right) \\
& \Rightarrow \lambda_{s d}+j \lambda_{s q}=\sigma L_{s} i_{s}+\underbrace{\left.L_{p s} / L_{p}\right) \bar{\lambda}_{p}}_{2}
\end{aligned}
$$

The above equations shows the voltage and flux equations of primary and secondary winding quantities

$$
\begin{aligned}
& \omega_{r m}=\left(\omega_{p}+\omega_{s}\right) / p_{r}=\omega_{p}\left(1+\omega_{s} / \omega_{p}\right) / p_{r} \\
& \dot{J}_{r m}=\underbrace{\frac{3 p_{r} L_{p s}}{2 L_{p}}\left(\lambda_{p d} i_{s q}+\lambda_{p q} i_{s d}\right)}_{T_{e}}-T_{L}-F \omega_{r m} \\
& P_{m}=T_{e} \omega_{r m}=\frac{T_{e} \omega_{p}}{p_{r}}+\frac{T_{e} \omega_{s}}{p_{r}}=P_{p}+P_{s}=P_{p}\left(1+\frac{\omega_{s}}{\omega_{p}}\right) \\
& Q=\frac{3 \omega_{p}}{2 L_{p}}\left(\lambda_{p}^{2}-\lambda_{p d} L_{p s} i_{s d}-\lambda_{p q} L_{p s} i_{s q}\right) \\
& \text { If } \omega_{s}=0 \text { then (7) becomes } \\
& \omega_{r m}=\omega_{p} / p_{r}=\omega_{s y n}
\end{aligned}
$$

If $\omega_{s}<0$, BDFRG is operates in sub-synchronous speed and secondary winding supplies power to the grid, if $\omega_{s}>$ 0 , it operates in super synchronous speed and consumes power from grid. 


\section{B. Primary Field Oriented Control (FOC)}

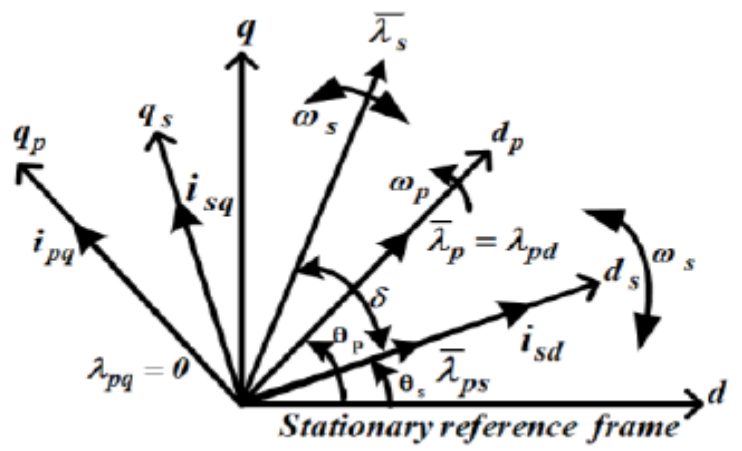

Figure1: Angular Positions of Primary and Secondary d-q Frames under Primary Field Orientation.

By observing the above figure it shows the $\lambda_{p}$ is aligned with d-axis. So that $\lambda_{p q}=0$ and $\lambda_{p d}=\lambda_{p}$.

Substituting the above values in $\mathrm{d}$ and $\mathrm{q}$ flux components then we get

$$
\begin{gathered}
\lambda_{p d}=L_{p} i_{p d}+L_{p s} i_{s d} \Rightarrow i_{s d}=\left(\lambda_{p d}-L_{p} i_{p d}\right) / L_{p s} \\
\text { And } L_{p} i_{p q}-L_{p s} i_{s q}=0 \Rightarrow i_{s q}=L_{p} i_{p q} / L_{p s}
\end{gathered}
$$

By using (13) the torque, power and reactive power equations can be represented as

$$
\begin{aligned}
& T_{e}=\frac{3 p_{r} L_{p s}}{2 L_{p}}\left(\lambda_{p d} i_{s q}\right)=\frac{3 p_{r}}{2}\left(\lambda_{p d} i_{p q}\right) \\
& P_{m}=\frac{3 p_{r} L_{p s}}{2 L_{p}}\left(\omega_{r m} \lambda_{p d} i_{s q}\right)=\frac{3 p_{r}}{2}\left(\omega_{r m} \lambda_{p d} i_{p q}\right) \\
& Q=\frac{3}{2} \omega_{p} \lambda_{p}\left(\frac{\lambda_{p d}-L_{p s} i_{s d}}{L_{p}}\right)=\frac{3}{2} \omega_{p} \lambda_{p} i_{p d}
\end{aligned}
$$

From the above all equations, it is clear that the torque and power depends on $i_{p q}$ and $i_{s q}$. The reactive power depends on $i_{p d}$ and $i_{s d}$. In the operation the maximum torque per inverter ampere (MTPIA) condition $i_{s d}{ }^{*}=0$ is considered for reducing the switching and secondary winding copper losses. By using this condition reactive power control is completely reduced.

\section{Active Power Based MRAS}

The MRAS system includes two models. One of this is reference model which is independent of speed and another one is adjustable or adaptive model which is dependent on rotor speed. The error between these two models is given to the adaptive system that gives the rotor speed as a output. The figure 2 gives the proposed P-MRAS. 


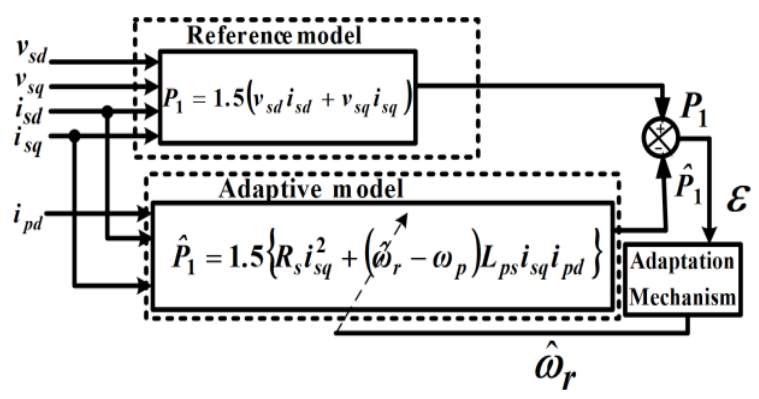

Figure 2: Block Diagram of Proposed P-MRAS.

The instantaneous active power of secondary winding as

$P_{1}=1.5\left(V_{s d} i_{s d}+V_{s q} i_{s q}\right)$

By means of (4) in d-q form, (17) may written as

$\widehat{P}_{1}=1.5\left[\left(R_{s} i_{s d}+\frac{d \lambda_{s d}}{d t}-\left(\omega_{r}-\omega_{p}\right) \lambda_{s q}\right)+\left(R_{s} i_{s q}+\frac{d \lambda_{s q}}{d t}+\left(\omega_{r}-\omega_{p}\right) \lambda_{s d}\right) i_{s q}\right]$

In above explanation the derivative terms in steady state condition becomes zero and using (6), equation (18) can be written as

$\widehat{\mathrm{P}}_{1}=\frac{3}{2}\left[\mathrm{R}_{\mathrm{s}}\left(\mathrm{i}_{\mathrm{sd}}^{2}+\mathrm{i}_{\mathrm{sq}}^{2}\right)+\mathrm{L}_{\mathrm{ps}}\left(\mathrm{i}_{\mathrm{pd}} \mathrm{i}_{\mathrm{sq}}+\mathrm{i}_{\mathrm{pq}} \mathrm{i}_{\mathrm{sd}}\right)\left(\omega_{\mathrm{r}}-\omega_{\mathrm{p}}\right)\right]$

Substitute (13) in (19), then we get

$\widehat{\mathrm{P}}_{1}=\frac{3}{2}\left[\mathrm{R}_{\mathrm{s}}\left(\mathrm{i}_{\mathrm{sd}}^{2}+\mathrm{i}_{\mathrm{sq}}^{2}\right)+\mathrm{L}_{\mathrm{ps}} \mathrm{i}_{\mathrm{sq}}\left(\omega_{\mathrm{r}}-\omega_{\mathrm{p}}\right)\left(\mathrm{i}_{\mathrm{pd}}+\frac{\mathrm{L}_{\mathrm{ps}}}{\mathrm{L}_{\mathrm{p}}} \mathrm{i}_{\mathrm{sd}}\right)\right]$

Hence equation(20) depends on rotor speed so that it will be consider as a adaptive model and equation (17) independent on rotor speed so it will be consider as reference model.

III. SIMULATION DIAGRAM OF BDFRG USING PI CONTROLLER

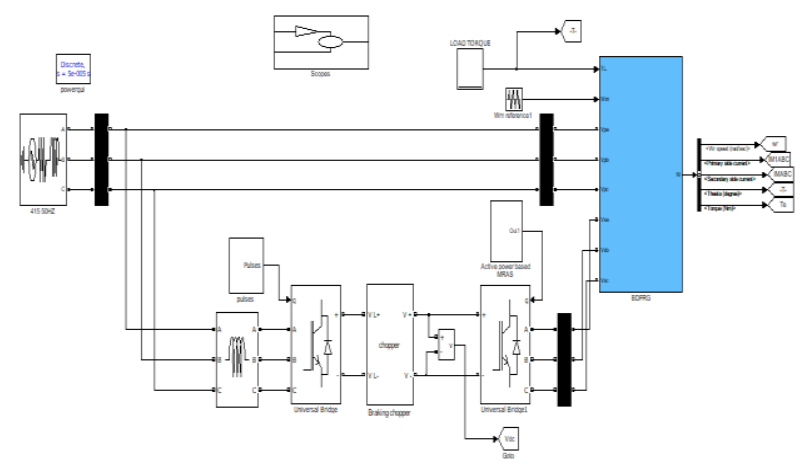

Figure 3: Simulink Block Diagram of BDFRG Using PI Controller.

\section{SIMULATION RESULTS OF P-MRAS USING PI- CONTROLLER}

Case-1: For constant load torque(-5Nm) and variable speed(59rad/s to $98 \mathrm{rad} / \mathrm{s})$ 


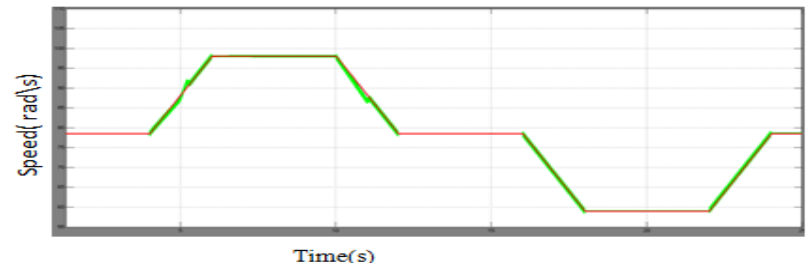

(a)

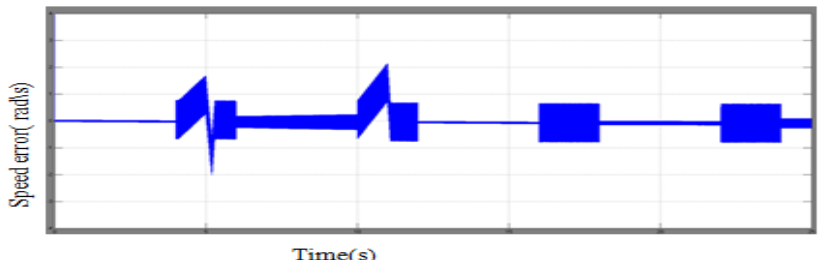

(b)

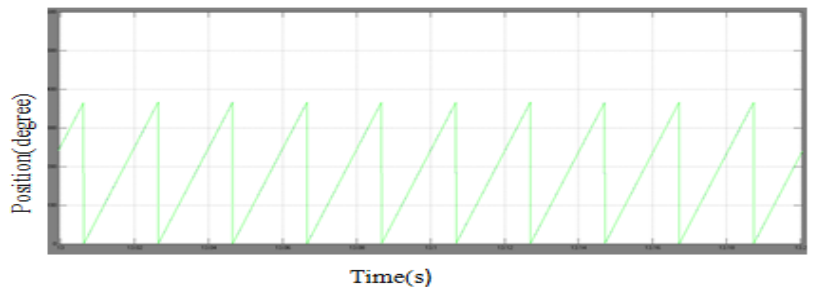

(c)

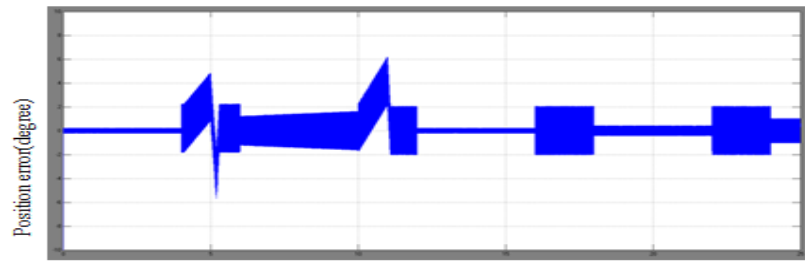

(d)

Figure 4: Dynamic Characteristics of P-MRAS of BDFRG using PI Controller

(a) Reference, Actual and Expected Speed (b) Speed Error

(c) Estimated and Actual Rotor Position Angle (d) Position Error.

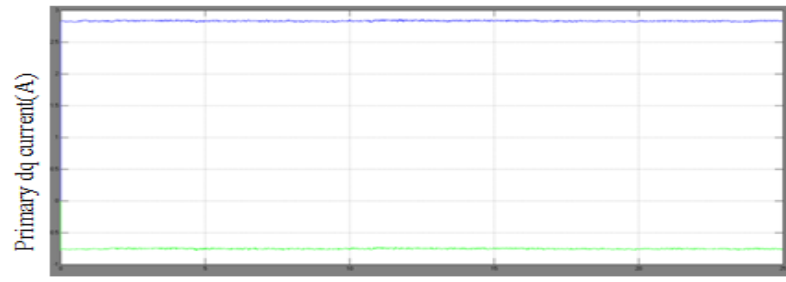

Time(s)

(a)

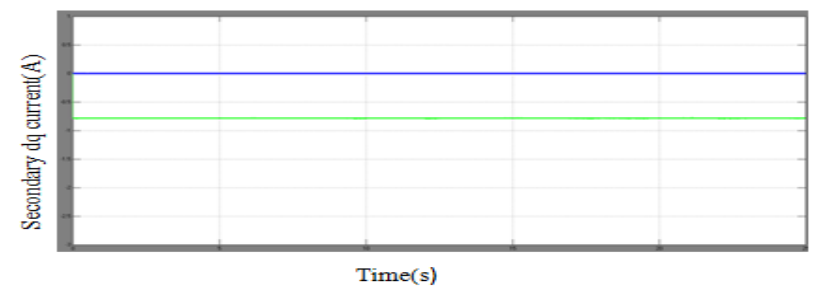

(b) 


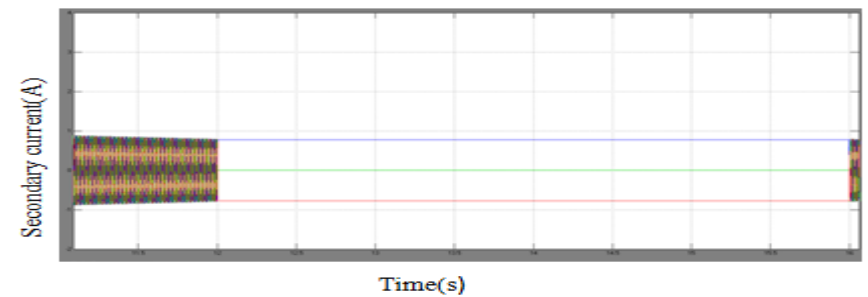

(c)

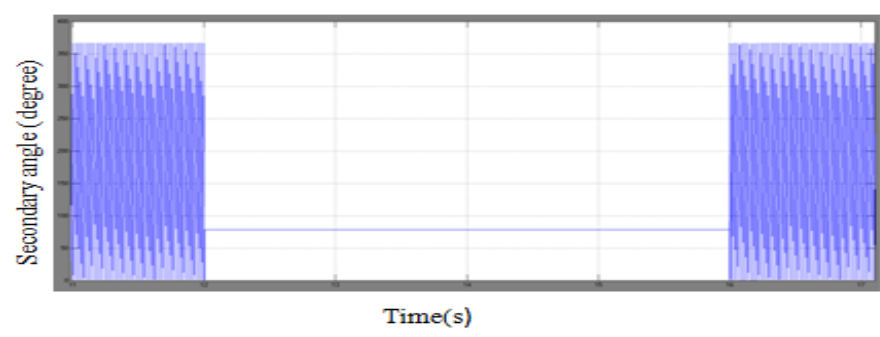

(d)

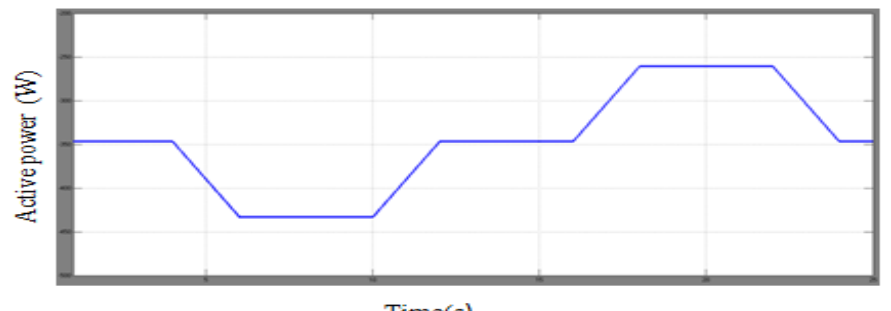

Time(s)

(e)

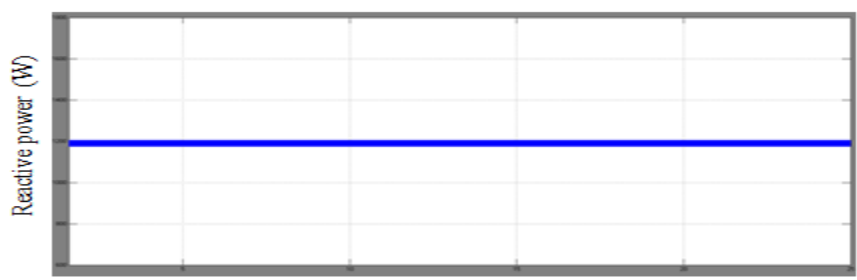

Time(s)

Figure 5: Dynamic Characteristics of P-MRAS of BDFRG using PI Controller(a) Primary Winding $d$ and $q$ Currents, (b) Secondary Winding d and q Currents, (c) Phase Sequence Reversal of 3- $\emptyset$ Secondary Currents (d) Secondary Reference Frame Angle, (e) Active Power, (f) Reactive Power.

Case-2: For constant load torque (-5Nm) and variable speed (59rad/s to $98 \mathrm{rad} / \mathrm{s})$

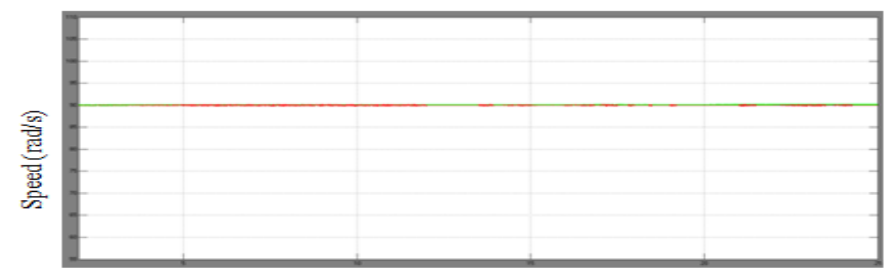

Time(s)

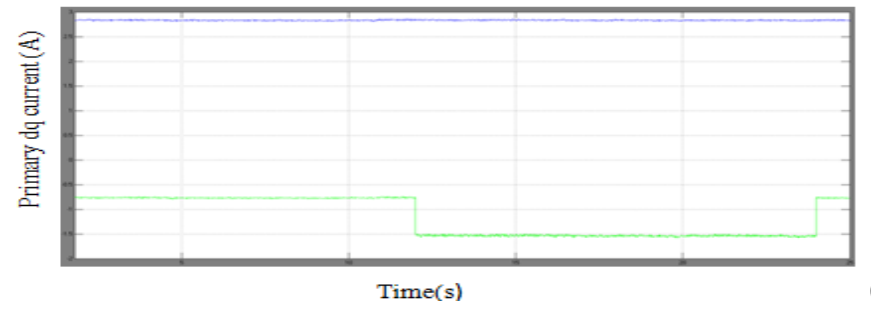

(b) 


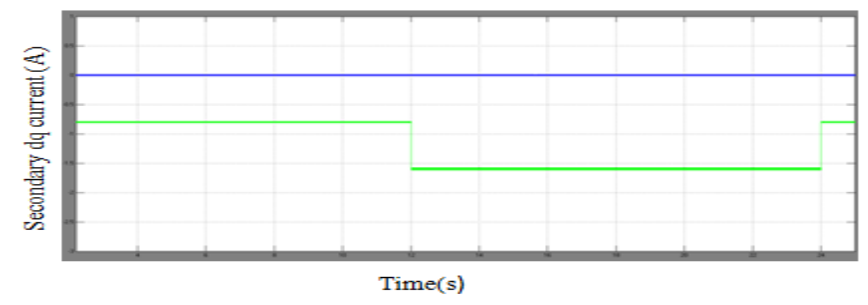

(c)

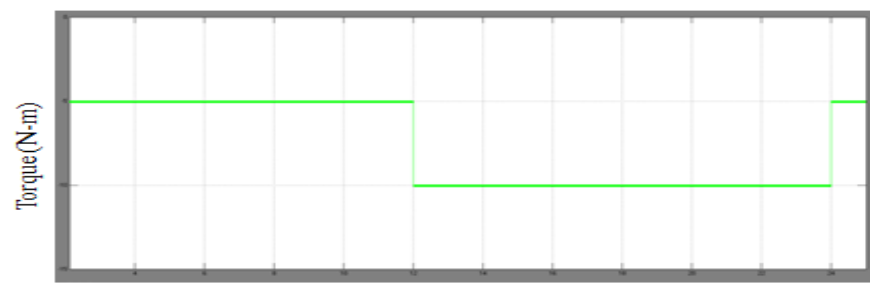

Time(s)

(d)

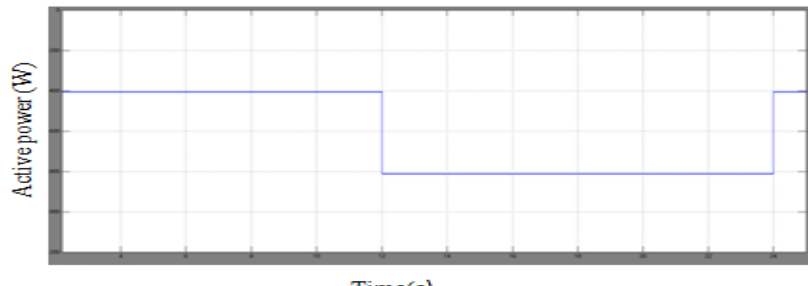

Time(s)

(e)

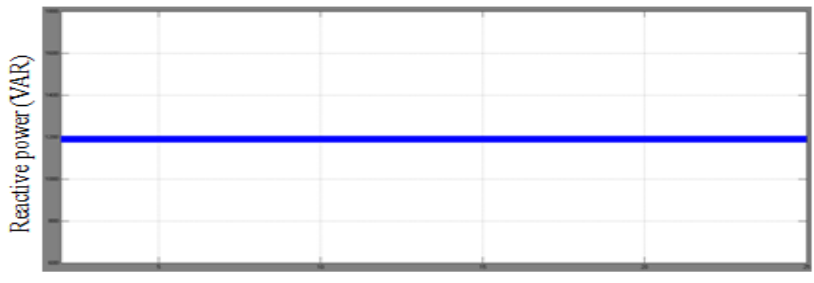

Times)

(f)

Figure 6: Dynamic Characteristics of P-MRAS of BDFRG using PI Controller (a) Reference, Actual and Expected Speeds, (b) Primary Winding d and q Currents, (c) Secondary Winding d and q Currents, (d) Load and Electromagnetic Torques, (e) Active Power, (f) Reactive Power.

\section{SIMULATION OF P-MRAS OF BDFRG USING ANFIS CONTROLLER}

Adaptive network based fuzzy inference system (ANFIS) is an artificial neural network (ANN) is the combination of Fuzzy systems and Neural Networks. The fuzzy inference system comprises of the fuzzy model proposed by Takagi-Sugeno. The fuzzy rules are framed in FLC system which output is tuned by using artificial neural networks methods.

In this paper consider two inputs and 7 fuzzified values. By this 49 Fuzzy rules are framed in fuzzy system. Beyond the 49 rules, the optimal rules are fired and the de-fuzzified output becomes the output neuron. It is used to generate the firing pulses of the Inverter Bridge which is used to control the speed of BDFRG drive.

The speed equation can be written as

$$
y=\frac{\sum_{i=1}^{R} \mu^{i} a_{i}^{i} x_{1}|\wedge| \sum_{i=1}^{R} \mu^{i} a_{q}^{i} x_{q}}{\sum_{i=1}^{R} \mu^{i}}
$$




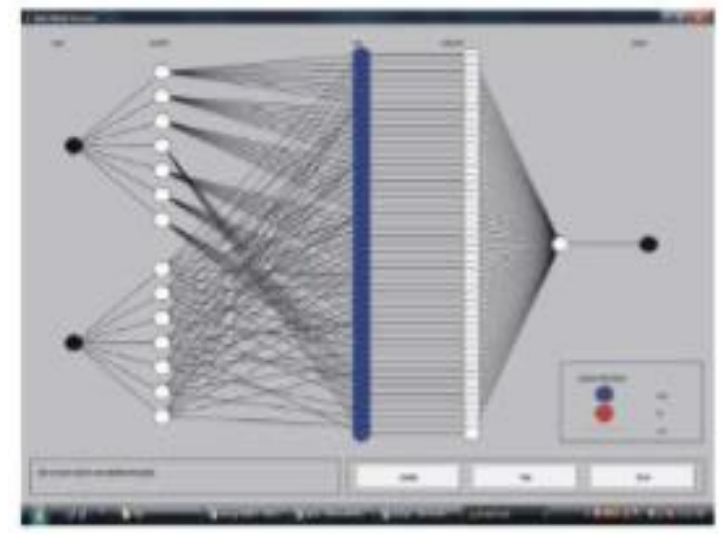

Figure 7: ANN Structure for ANFIS Controller.

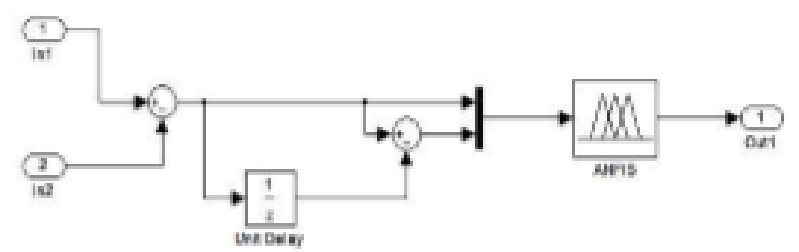

Figure 8: Replace of PI Controller By ANFIS Controller In Proposed System.

\section{SIMULATION RESULTS OF P-MRAS USING ANFIS -CONTROLLER}

Case-1: For constant speed (90rpm) and variable load torque (-5Nm to $-10 \mathrm{Nm})$.

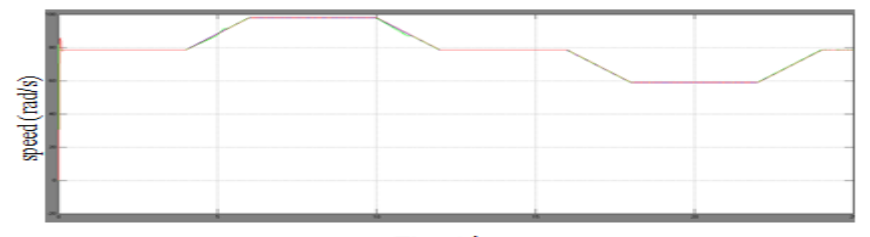

Time(s)

(a)

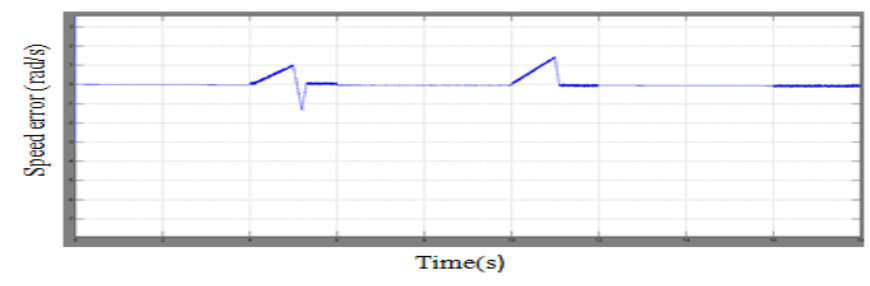

(b)

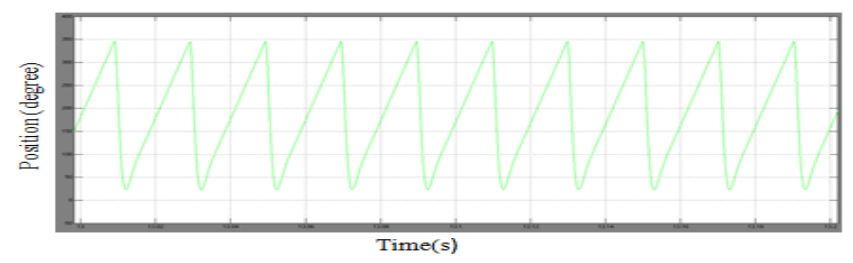

(c) 


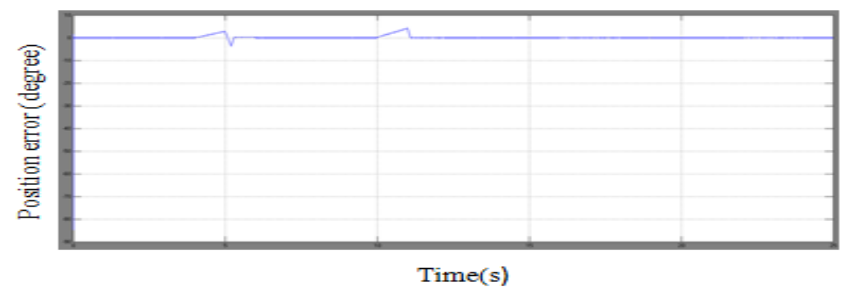

(d)

Figure 9: Dynamic Characteristics of P-MRAS of BDFRG using ANFIS Controller (a) Reference, Actual and Expected Speeds, (b) Speed Error, (c) Measured and Real Rotor Angle, (d) Position Error.

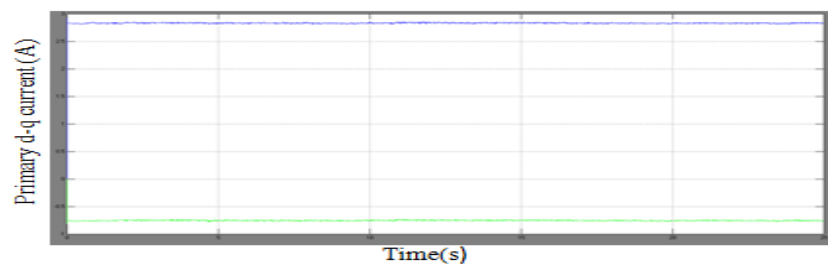

(a)

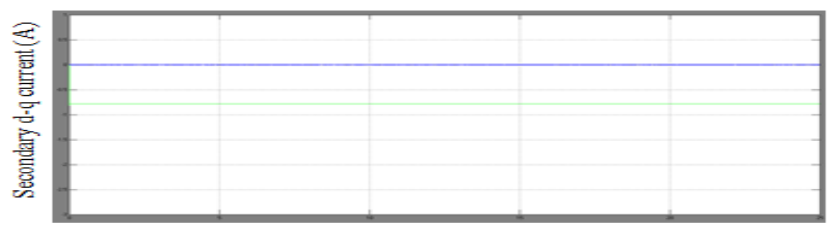

(b)

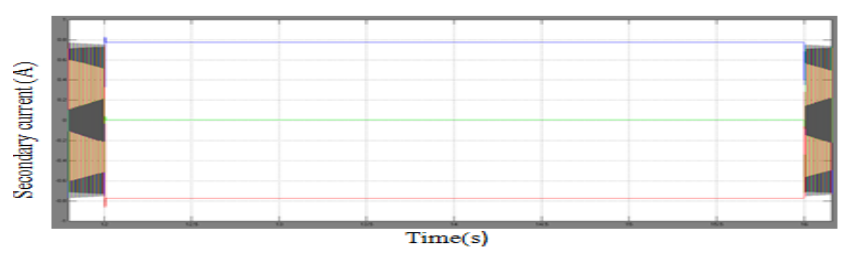

(c)

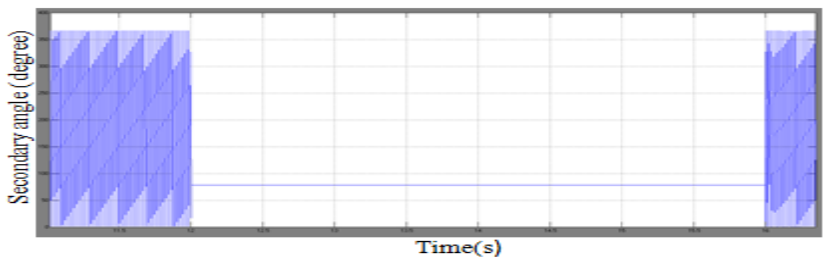

(d)

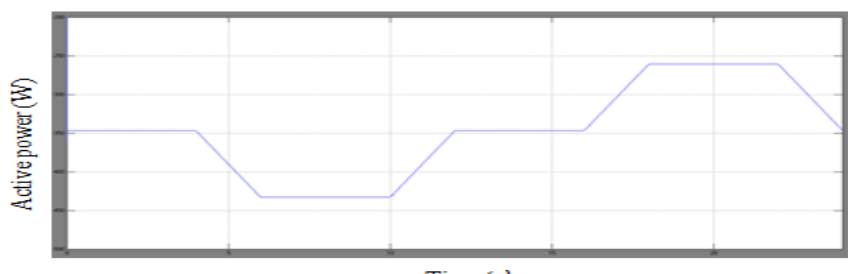

Time(s)

(e)

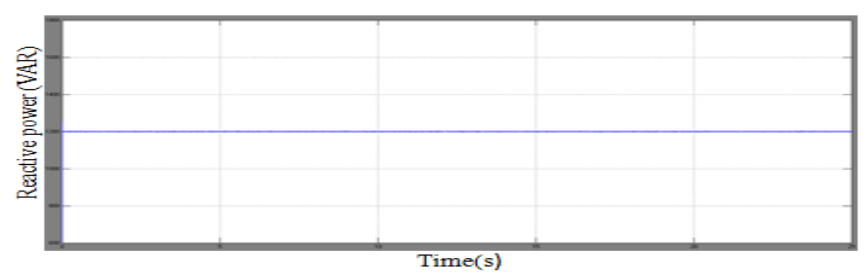

(f)

Figure 10: Dynamic Characteristics of P-MRAS of BDFRG using ANFIS Controller (a) Primary Winding d and q Currents, (b)Secondary Winding d and q Currents, (c) Phase Sequence Reversal of 3- $\varnothing$ Secondary Currents (d)Secondary Reference Frame Angle, (e)Active Power, (f) Reactive Power. 
Case-2: For constant speed (90 rad/s) and variable loadtorque(-5Nm to $-10 \mathrm{Nm})$

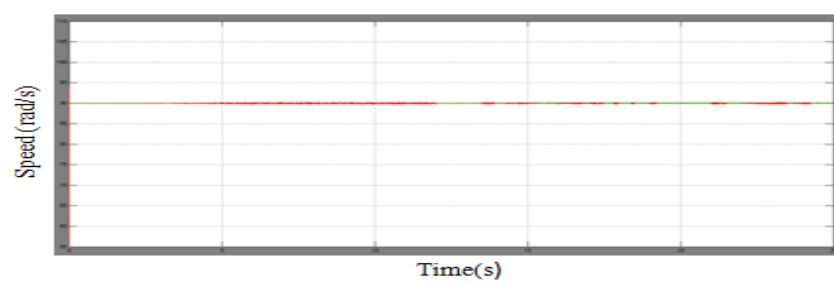

(a)

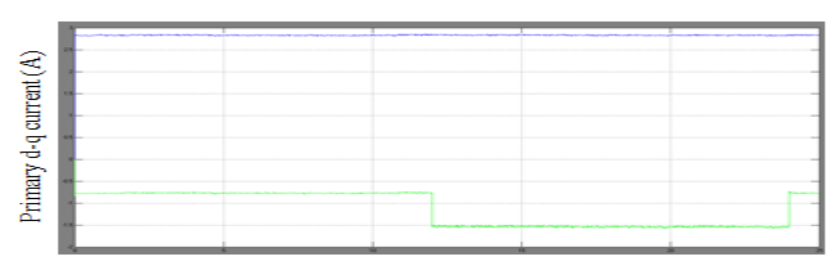

Time(s)

(b)

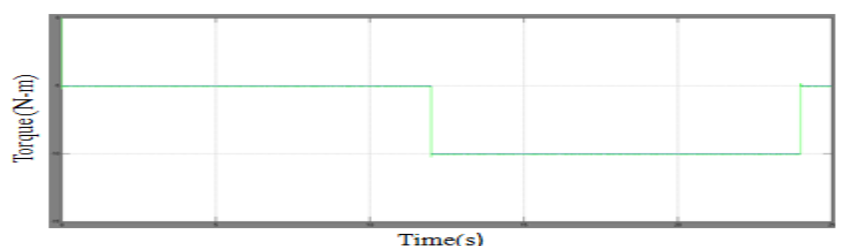

(c)

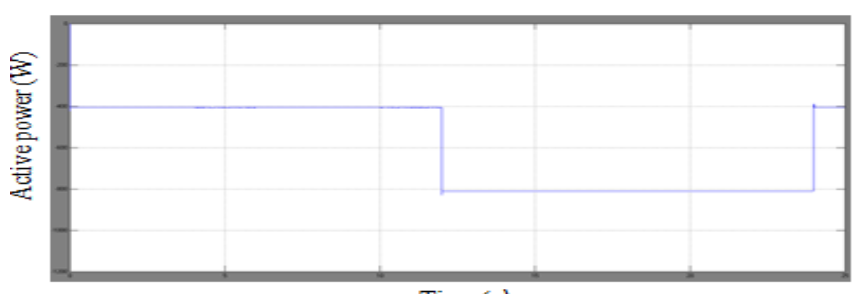

Time(s)

(d)

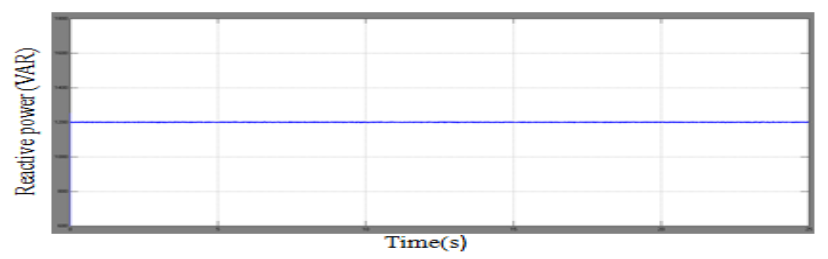

(e)

Figure 11: Dynamic Characteristics of P-MRAS of BDFRG using ANFIS Controller (a) Reference, Actual and Expected Speeds, (b) Primary Winding d and q Currents, (c) Load and Electromagnetic Torques, (d) Active Power, (e) Reactive Power.

Table 1: Comparison Between Pi And Anfis Controller

\begin{tabular}{|l|l|l|}
\hline \multicolumn{1}{|c|}{ Parameters } & \multicolumn{1}{c|}{ PI Controller } & \multicolumn{1}{c|}{ ANFIS Controller } \\
\hline Estimated Speed $\left(\widehat{\omega}_{r}\right)$ at super synchronous speed(98rad/s) & $98.14 \mathrm{rad} / \mathrm{s}$ & $98.04 \mathrm{rad} / \mathrm{s}$ \\
\hline Estimated speed $\left(\widehat{\omega}_{r}\right)$ at sub synchronous speed(59rad/s) & $59.15 \mathrm{rad} / \mathrm{s}$ & $59.02 \mathrm{rad} / \mathrm{s}$ \\
\hline Speed error & $2 \mathrm{rad} / \mathrm{s}$ & $1.4 \mathrm{rad} / \mathrm{s}$ \\
\hline
\end{tabular}

\section{CONCLUSIONS}

This paper proposed a sensorless speed estimation of BDFRG using P-MRAS under primary field oriented control. In this scheme there is no need of sensor for measuring secondary quantities. These are measured with the help of primary voltages and currents. In MRAS, the error between adaptive model and reference model given to the adaptive mechanism to estimate rotorspeed. When the system operates with PI Controller, the value of estimated speed 98.14rad/s at super synchronous 
speed, 59.15rad/s at sub synchronous speed and speed error 2rad/s is observed.ANFIS controller is used in place of PI controller for improving the dynamic performance and reducing the speed error. By considering ANFIS controller, estimated speed improved to $98.04 \mathrm{rad} / \mathrm{s}$ at high synchronous speed and 59.02rad/s at low synchronous speed. Thus the speed error reduced to $1.4 \mathrm{rad} / \mathrm{s}$.

\section{REFERENCES}

1. M. Jovanovic, R. Betz and J. Yu, "The use of doubly fed reluctance machines for large pumps and wind turbines," IEEE Trans. Ind. Appl., vol. 38, no. 6, pp. 1508-1516, Nov./Dec. 2002.

2. J. Carroll, A. McDonald and D. McMillan, "Reliability comparison of wind turbines with DFIG and PMG drive trains, "IEEE Trans. Energy Covers, vol. 30, no. 2, pp. 663-670, June 2015.

3. F. Wang, F.Zhang and L.Xu, "Parameter and performance comparison of doubly fed brushless machine with cage and reluctance rotors," IEEE Trans. Ind. Appl, vol. 38, no. 5, pp. 1237-1243, Sept./Oct. 2002.

4. M. Knight, E. Betz and D. Dorrell, "Design and analysis of brushless doubly fed reluctance machines," IEEE Trans. Ind. Appl., vol. 49, no. 1, pp. 50-58, Jan./Feb. 2013

5. S. Ademi and M. Jovanovic, "Vector control methods for brushless doubly-fed reluctance machines, "IEEE Trans. Ind. Electron., vol. 62, no. 1, pp. 96-104, Jan. 2015.

6. M. Jovanovic, J. Yu and E. Levi, "Encoderless direct torque controller for limited speed range applications of brushless doubly fed reluctance motors, "IEEE Trans. Ind. Appl., vol. 42, no. 3, pp. 712-722, May/June 2006

7. J. Ha and S. Sul, "Sensorless field-orientation control of an induction machine by high-frequency signal injection," IEEE Trans. Ind. Appl., vol. 35, no. 1, pp. 45-51, Jan./Feb. 1999.

8. J. Laowanitwattana, and S. Uatrongjit, "Estimation of induction motor states and parameters based on extended kalman filter considering parameter constraints, " in Proc. of SPEEDAM, Capri, Italy, Jul. 28, 2016, pp.755-760

a. Teja, C. Chakraborty, S. Maiti and Y. Hori, "A new model reference adaptive controller for four quadrant vector controlled induction motor drives, "IEEE Trans. Ind. Electron., vol. 59, no. 10, pp. 3757-3767, Oct. 2012.

9. K. Kiran, S. Das and A. Sahu, "Sensorless speed estimation and control of BDFRM driveusing MRAS," in IEEE International conference of PEDES, Trivandrum, India, Dec. 2016.

10. K. Kiran and S. Das, "Implementation of reactive power-based MRAS for sensorless speed control of BDFRM drive, "IET Power Electron, vol. 11, no. 1, pp. 192-201, Feb. 2018.

11. M. Kumar, S. Das and A. K. Sinha, "Sensorless speed control of brushless doubly-fed reluctance machine for pump storage and wind power application," in IEEMA Engineer infinite conference (eTechNxT), New Delhi, India, 13-14 March 2018.

12. Mukeshkumar, Sukanta Das, "Sensorless Speed Estimation of Brushless Doubly-Fed Reluctance Generator using Active Power Based MRAS, ” in IEEE Transactions on Power Electronics, July 2018.

13. Deshpande, Shripad V., and P. R. Devale. "Recent trends in using wireless sensor networks in industrial environment." International Journal of Computer Networking 3.3 (2013).

14. Chourasia, R. C., and A. K. Bhardwaj. "Design Estimation Of Brushless SEDC Motor For Speed Control By Using Various Controllers. "IJEEER ISSN (P) (2014).

15. Chowdary, A. Hemant, and PV Ramana Rao. "Adaptive neuro-fuzzy based pss for Multi Machine Systems. "International Journal of Electrical and Electronics Engineering Research (IJEEER) 3 . 2, Jun 2013, 223-232 
16. MN, Kalaivani, and K. Balachander. "A Review on Certain Wind Turbine Models."International Journal of Mechanical and Production Engineering Research and Development (IJMPERD) 8. 4, Dec 2018, 201-217

\section{AUTHORS PROFILE}

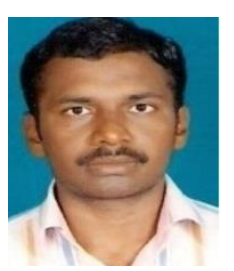

Dr. M. ANKARAO, received his Bachelor's degree from Andhra University in Electrical \& Electronics Engineering in 2006. He received Master's degree in Power and Industrial Drives in 2010 from JNTU Anantapuramu. He received his Ph.D in 2020 from JNTU Ananthapuramu, India. He is currently working as Assistant professor in Electrical Department of JNTUA College of Engineering, Ananthapuramu, India. He has teaching experience 10 years. His research interest areas include Electrical Machines, Electrical Drives and Power Electronic.

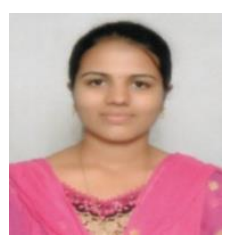

G. PRAVALLIKA, received her Bachelor's degree from GATES Institute of Engineering, Gooty, india in the year of 2017 from Electrical and Electronics Engineering. She is currently working towards her Master's degree from JNTUA college of Engineering, Anantapuramu, India, in Power \& Industrial Drives specialization from the department of EEE, 2020. Her research interests are Power Electronics and Electrical Machines.

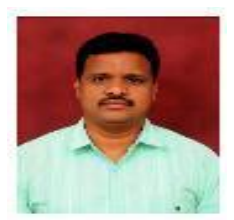

S. SRIDHAR,received his B.Tech degree in Electrical \&Electronics Engineering in 2003 from JNTU Hyderabad. He completed M.Tech in JNTU Hyderabad in the specialization ofElectrical Machines \&Industrial Drives in 2006 . He is working towards his PhD from JNTU Ananthapuramu, India. He is currently working as Assistant professor in Electrical Department of JNTUA College of Engineering, Ananthapuramu, India. He has teaching experience 8 years. 